\title{
3. Scott Waide, Maseratis and EMTV ... how a public outcry restored media freedom
}

Commentary: 'It's like we are operating in a bubble,' says EMTV deputy news editor Scott Waide from Papua New Guinea at the Melanesia Media Freedom Forum (MMFF). 'But when you start reaching out, talking to others in the region, you find that you are not actually alone in this. The experiences are similar. The intensity varies, but the take home for me is that nobody should be alone to handle their problems on their own.'

Keywords: Australia, censorship, Fiji, media freedom, Papua New Guinea, television

\section{FRED WESLEY}

Editor-in-chief, The Fiji Times, Suva

T'S A wrap at the inaugural Melanesia Media Freedom Forum (MMFF) in Brisbane on Tuesday, 12 November 2019. In this mega city, the little grass patch in the confines of Griffith University's complex along Grey Street offers a sort of reprieve from the hustle and bustle of the city's streets. The temperature had been hovering between a low of 17 degrees Celsius and a high of 27.

As the afternoon sun slowly ebbs away into another Brisbane evening, the air is cooler. In the background, against the din of the evening traffic along Grey Street and the main Vulture Street, a few minutes' walk south of the campus, a dance group struts its stuff.

Scott Waide, a senior journalist from EMTV, almost nonchalantly, points out they are from Papua New Guinea. The dance form, attire, and song confirm this for him. They are like trademarks, a sort of rubber stamp of origin perhaps. But there are little 'identifiers' that he was able to immediately pick out as the dance group went through their choreographed moves. The graceful sways of their hips, and placement of their feet and arms, in synch with the melodious sounds of the accompanying serenade, consolidate his opinion. It's not lost at all among his colleagues.

It's a sort of thankful respite at the end of two days of powerful discussions at room SO2-7. Discussions had kicked off with a panel touching on the issue 


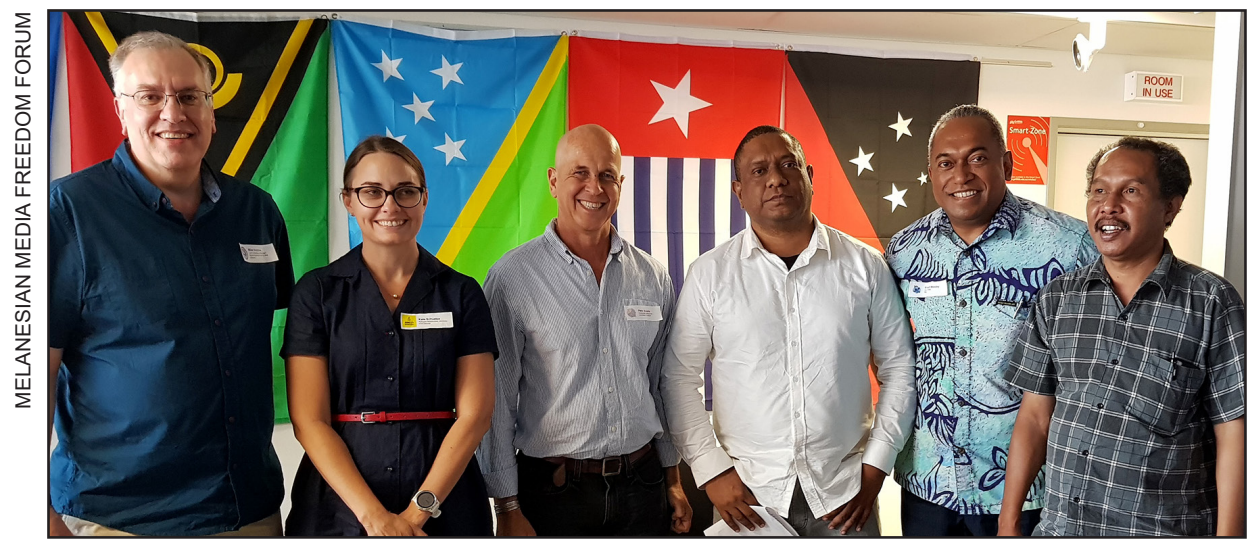

Figure 1: Paul Murphy (International Federation of Journalists), Kate Schuetze (Amnesty International), Peter Greste (Alliance for Journalists' Freedom), Scott Waide (EMTV), Fred Wesley (The Fiji Times), Victor Mambor (Tabloid Jubi) during the Melanesia Media Freedom Forum (MMFF) summit at Griffith University in Brisbane, Queensland, in November 2019.

of why media freedom is so important in Melanesia, and the issues journalists faced daily and what they hoped to achieve looking to the future. The plenary session, appropriately tagged 'In conversation', brought together a host of varying opinions and scenarios from journalists from Bougainville, Fiji, Papua New Guinea, Solomon Islands, Vanuatu and West Papua.

Sections of the Media Industry Development Authority Act (formerly the Decree) were raised as a discussion point. Section 22, on content regulation, requires media organisations in Fiji to ensure that their content must not include material which:

- $\quad$ is against the public interest or order;

- $\quad$ is against national interest; or

- creates communal discord.

Section 23 reads: 'The content of any print media which is in excess of 50 words must include a byline and wherever practical, the content of any media service must include a byline.' The penalties for these breaches are fines not exceeding F\$100,000 for a media organisation or, in the case of a publisher or editor, a fine not exceeding $\$ 25,000$ or imprisonment for a term not exceeding two years or to both.

It was an opportunity to discuss the issue with fellow journalists from around the region, raise awareness and engage in open discussions with international experts. You could sense passion, and touches of concern emanating from the discussions.

Waide knows too well what it means to be pushed into a corner. In November 


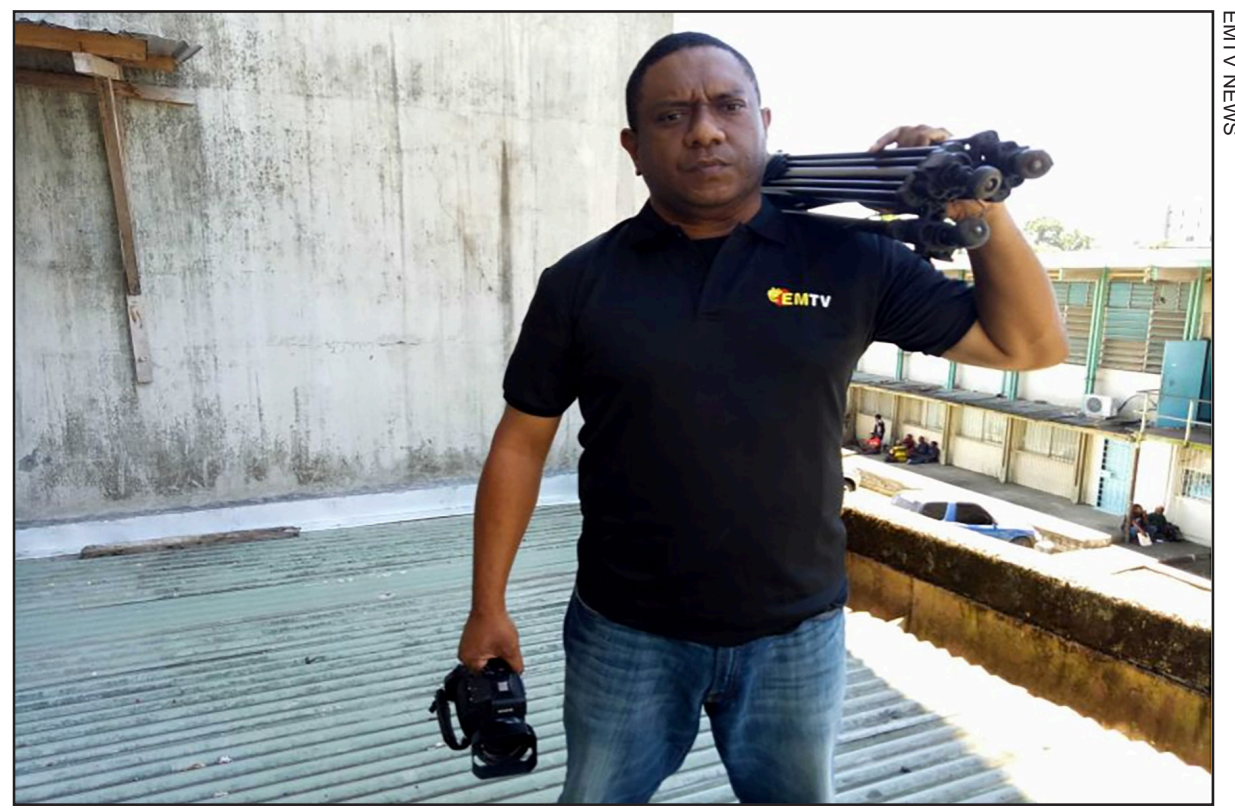

Figure 2: Scott Waide of EMTV: 'We should also be preparing younger journalists to take on these roles so that in the event that we get arrested and are sent to jail, somebody takes over.'

2018, the ABC reported Waide's predicament after he had aired a story critical of government spending.

Waide, the deputy regional head of news for EMTV in Lae was suspended (EMTV suspends senior journalist Scott Waide, 2018) for broadcasting a report from a New Zealand TV station criticising PNG's purchase of 40 luxury Maseratis (Jacinda Ardern says she won't be travelling in a Maserati, 2018). The report came in the wake of anger over government spending during the Asia Pacific Economic Cooperation (APEC) conference.

The government was accused of a cover up by the Opposition. Waide was reinstated in the wake of a massive public backlash (PNG journalist reinstated, 2018; Scott Waide reinstated, 2018).

'The forum was good because it brought together Melanesian journalists,' Waide says. 'A lot of times we think we operate in isolation.

'It's like we are operating in a bubble. But when you start reaching out, talking to others in the region, you find that you are not actually alone in this. The experiences are similar. The intensity varies, but the take home for me is that nobody should be alone to handle their problems on their own.

'We should be talking together on a greater scale. And we should also be preparing younger journalists to take on these roles so that in the event that we get arrested and are sent to jail, somebody takes over. That has worked for us. 
'I think this is a good start. We should have more of this and generally build relations.

'These are really important. And it's very Melanesian to sit down in a group and iron out issues, talk about issues, with no time limit.

'As soon as the objective is achieved, everybody agrees and we move on.'

'No time limit, no set agenda, but identifying issues, and talking about them until we reach common understanding.

'My message for aspiring journalists, is to go back to our roots, reach out. Form relationships that should be established. It should not be just a small circle operating out of PNG. It should be a wider circle, Fiji, Vanutau, Solomon Islands and so on. It should be greater than what we have now.'

Renowned former ABC investigative journalist Sean Dorney echoed many of his sentiments (Sean Dorney, n.d.). Dr Tess Newton-Cain, one of the key figures behind the organising of the forum speaks highly of Dorney's role.

'Sean Dorney is living with motor neurone disease and he has to be careful that he doesn't overdo things,' she said.

'At the end of the two days he said to me, "Pauline kept asking me if I was $\mathrm{OK}$, if I was getting tired but I said to her, being here and being with these journalists is giving me energy, it's giving me a boost".'

The disease hasn't knocked off Dorney's jokes though, or his witty remarks.

'This has been one of the really good experiences since I have been in Brisbane,' he offered.

'I left the ABC in 2014 but I have kept a very close interest in what is going on in the Pacific. I was absolutely pleased. It is so important that when the media is under pressure these days, it is so important that we as journalists get together and reinforce that solidarity that we have had.

'The forum has been hugely energetic for me, meeting journalists who I have known for a very long time. I have nothing but enormous respect for them.

'There is no doubt about it, it is becoming increasingly difficult to be a journalist and do your job in the Melanesian region. I think we should keep this going, keep campaigning for the governments in our region, that media freedom is the absolute bulwark in these countries.

'The takeaway I am taking from this is unity.

'For journalists from the region, there is a sense of community, there is a sense that we are united.

'We do have threats, we do have problems, but with the support of each other and our colleagues in countries like New Zealand and Australia, we can fight against oppressive and restrictive problems that many of us face. Look I have nothing but admiration for the people who came to this forum.

'I think we have actually achieved something in the past few days and we have the opportunity to keep this going for some time.' 
It's that hope, that commitment and passion that is embracing. It's the catalyst regional journalists need to face the future.

In the face of great challenges, something Dorney said stands out.

'Journalism is an honourable profession. But we face increasing threats and increasing problems where those in authority seem to think we are the enemy rather than their friends, rather than the ones who are sort of keeping these democracies open and thriving.'

The dancers have finished their item. Discussions have moved away from the topics that are close to the hearts of the participating journalists. It's time to sit back, relax, throw in a bit of small talk, mingle, exchange business cards, and be embraced by the Brisbane night.

Tomorrow is another day. The journalistic instinct though is pretty hard to put down. There are challenges. But there is hope.

\section{References}

EMTV suspends senior journalist Scott Waide over NZ Maserati news story (2018, November 25). Asia Pacific Report-Pacific Media Watch. Retrieved from https:// asiapacificreport.nz/2018/11/25/emtv-suspends-senior-journalist-scott-waide-overmaserati-news-story/ Also, EMTV television news 17 November 2018. [Video]. Retrieved from https://youtu.be/76CxGr62aZ8

Jacinda Ardern says she won't be travelling in a Maserati at Papua New Guinea APEC (2018, November 16). Television New Zealand. [Video] Retrieved from https:// www.tvnz.co.nz/one-news/new-zealand/jacinda-ardern-says-she-wont-travelling-inmaserati-papua-new-guinea-apec

PNG journalist reinstated (2018, November 27). RNZ Pacific. Retrieved from https:// www.rnz.co.nz/international/pacific-news/376888/png-journalist-scott-waidereinstated

Scott Waide reinstated - 'thank you' message from EMTV journalist (2018, November 26). Asia Pacific Report- Pacific Media Watch. Retrieved from https://asiapacificreport.nz/2018/11/26/scott-waide-reinstated-thank-you-message-from-emtv-journalist/ Sean Dorney (n.d.) Wikipedia. Retrieved from https://en.wikipedia.org/wiki/Sean_Dorney

Fred Wesley is editor-in-chief of The Fiji Times and was awarded the news media executive of the year prize at the Asia Pacific Media Awards after his courageous stand against the Fiji government in a sedition case filed against his newspaper. The Fiji Times, oldest and the most influential newspaper in Fiji, celebrated 150 years in 2019. An earlier version of this article was published in the Fiji Times on 23 November 2019 under the title 'Matters affecting Pacific journos'. fwesley@fijitimes.com.fj 